\title{
Extreme Rituals Promote Prosociality
}

Psychological Science

$\mathrm{XX}(\mathrm{X}) 1-4$

(C) The Author(s) 2013

Reprints and permissions:

sagepub.com/journalsPermissions.nav DOI: $10.1177 / 0956797612472910$ pss.sagepub.com

\author{
Dimitris Xygalatas $^{1,2,3}$, Panagiotis Mitkidis ${ }^{1,2,3}$, Ronald Fischer ${ }^{4}$ \\ Paul Reddish ${ }^{2,4}$, Joshua Skewes ${ }^{1,3}$, Armin W. Geertz ${ }^{1,3}$, \\ Andreas Roepstorff ${ }^{1,3}$, and Joseph Bulbulia ${ }^{2,5}$ \\ ${ }^{1}$ Department of Culture and Society, Aarhus University; ${ }^{2}$ LEVYNA Laboratory for the Experimental \\ Research of Religion, Masaryk University; ${ }^{3}$ Interactive Minds Centre, Aarhus University; ${ }^{4}$ School of \\ Psychology, Victoria University of Wellington; and ${ }^{5}$ School of Art History, Classics and Religious \\ Studies, Victoria University of Wellington
}

Received 8/22/12; Revision accepted 11/30/12

Extreme rituals entail excessive costs without apparent benefits, which raises an evolutionary cost problem (Irons, 2001). It is argued that such intense rituals enhance social cohesion and promote cooperative behaviors (Atran \& Henrich, 2010; Durkheim, 1912). However, direct evidence for the relation between ritual intensity and prosociality is lacking. Using economic measures of generosity and contextually relevant indicators of group identity in a real-world setting, we evaluated prosocial effects from naturally occurring rituals that varied in severity.

Our study took place in Mauritius, a multicultural country where citizens frequently negotiate between parochial ethnic-religious and inclusive national identities (Ng \& Verkuyten, 2010). We examined two rituals that were part of the annual Hindu festival of Thaipusam, one of the most widely celebrated religious festivals the world over: a low-ordeal ritual involving singing and collective prayer (Fig. 1a) and a high-ordeal ritual (Kavadi; Fig. 1b) involving body piercing with multiple needles and skewers, carrying heavy bamboo structures, and dragging carts attached by hooks to the skin for over $4 \mathrm{hr}$ before climbing a mountain barefooted to reach the temple of Murugan.

On the basis of evolutionary perspectives on the social functions of religious practices (Norenzayan \& Shariff, 2008; Sosis, 2003) and recent evidence on extreme rituals and empathic arousal (Konvalinka et al., 2011), we predicted that higher ritual intensity would lead to greater generosity for both performers and observers. We also predicted an effect of ritual intensity on social identification. Classical findings from psychology (Aronson \& Mills, 1959; Festinger, 1957; Tajfel, Billig, Bundy, \& Flament, 1971) and evolutionary perspectives on parochial altruism (Choi \& Bowles, 2007; Ginges, Hansen, \& Norenzayan, 2009) suggest that ritual intensity is associated with subgroup identification. However, recent intergroup theories
(Gaertner \& Dovidio, 2000; Hornsey \& Hogg, 2000) suggest that in Hindu-dominated Mauritius, where Thaipusam is celebrated on a national scale, the ritual of the majority religious group affirms the inclusive nature of the superordinate Mauritian national identity.

\section{Method}

Participants were 86 males, all belonging to the same religious and social group: 19 were high-ordeal performers of the Kavadi, 32 were high-ordeal observers (nonperforming participants who walked alongside performers), and 35 were low-ordeal performers who participated in a collective prayer 3 days earlier. Observers were typically related to the performers and had previously performed the Kavadi. All participants took part in both rituals, although each was tested in only one, selected randomly to avoid self-selection biases. Both rituals occurred at the same venue and had similar durations and numbers of attendants. Participants were recruited by local assistants immediately after each ritual. Following the ritual, they entered a room near the temple and answered a questionnaire before engaging in a donation task. The questionnaire was delivered on computer screens by Presentation software (Version 0.70; NeuroBehavioral Systems, www .neurobs.com). Participants used the arrow keys on a standard keyboard to move a cursor along unmarked sliding scales anchored by verbal labels in the local Creole language.

We operationalized prosociality in terms of behavior (charity) and attitudes (social identification). Identity was measured on a scale anchored by the parochial

\section{Corresponding Author:}

Dimitris Xygalatas, Department of Culture and Society, Aarhus University, Building 1483, 3rd Floor, Aarhus 8000, Denmark

E-mail: xygalatas@mac.com 
a

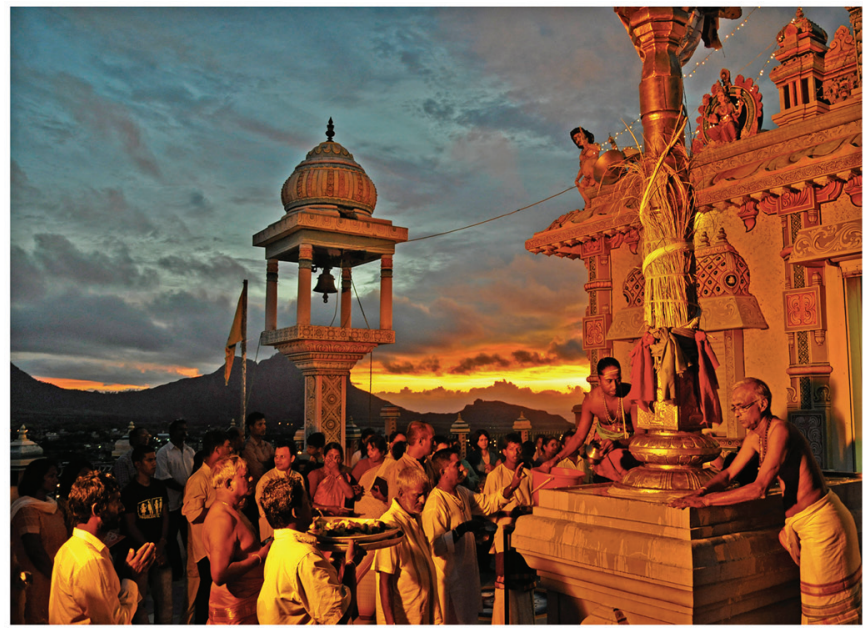

b

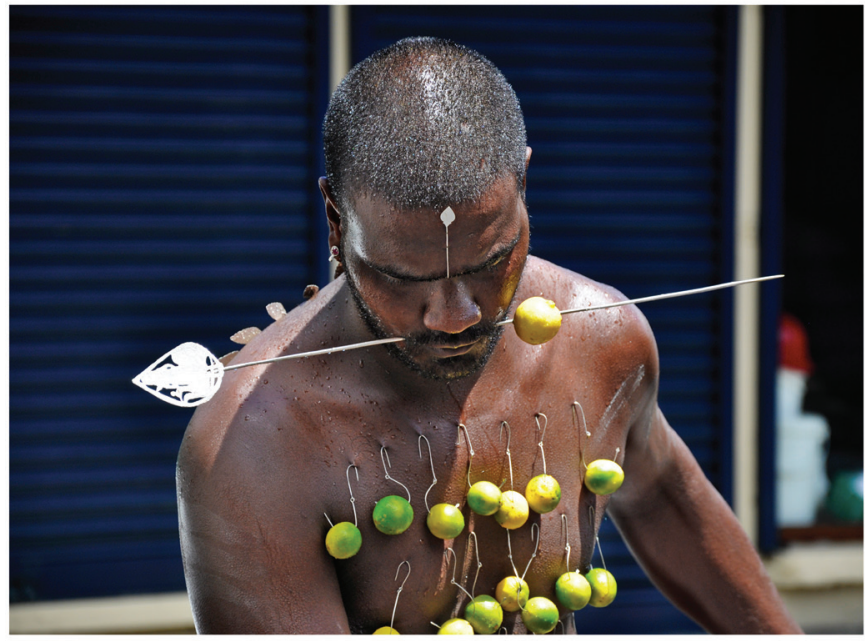

C

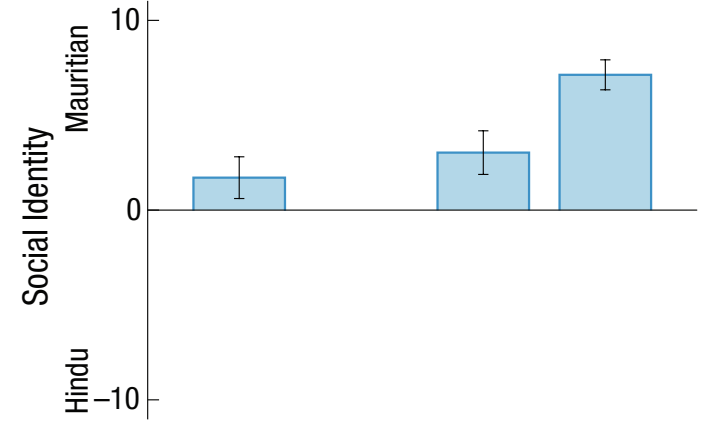

d

e
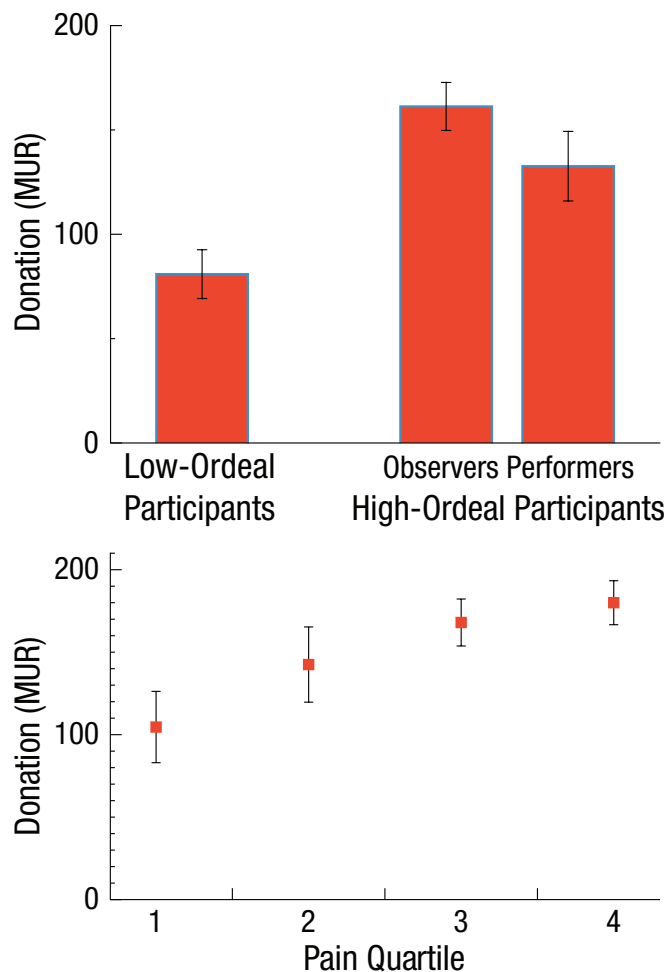

Fig. 1. Photos from the annual Hindu festival of Thaipusam and results showing the effects of ritual intensity. Subjects were participants in a low-ordeal ritual involving singing and collective prayer (a) and performers in or observers of a high-ordeal ritual involving body piercing with multiple needles, hooks, and skewers (b). Mean ratings of social identity (parochial Hindu vs. inclusive Mauritian; c) are shown as a function of group. Mean donations in Mauritian rupees (MUR) are shown both (d) as a function of group and (e) as a function of the highordeal group, collapsed across performers and observers $(n=51)$ and divided into quartiles based on participants' pain ratings. Error bars in (c) through (e) represent standard errors of the mean.

ethnic-religious Hindu identity at one end and by the superordinate inclusive national Mauritian identity at the other. Religiosity was measured in terms of belief and temple attendance. These questions were adapted from the World Values Survey (2012, Items V145 and V147) in discussion with focus groups. Pain was measured on a scale anchored by no pain at all and most painful thing ever. The question "how painful is it to perform the Kavadi?" allowed us to examine experienced pain for performers and perceived pain for observers. After completing the questionnaire, participants were paid 200 rupees in coins of 20 rupees (approximately 2 days' salary for an unskilled worker) for participating in the study. On leaving, participants entered a booth, where they had the opportunity to anonymously donate any part of this money to the temple. A system of numbered envelopes and questionnaires enabled us to track individual donations while maintaining anonymity. 


\section{Results and Discussion}

Low-ordeal participants donated an average of 80.91 Mauritian rupees $(S D=69.18)$, high-ordeal observers donated 161.25 rupees $(S D=65.04)$, and high-ordeal performers donated 132.63 rupees $(S D=72.79$; Fig. $1 \mathrm{~d})$. An analysis of variance (ANOVA) showed a main effect of group on donation, $F(2,83)=11.78, p<.001$. The difference between charity in the low-ordeal group and highordeal group (performers and observers combined) was significant, $t(84)=-4.61, p<.001$, whereas that between high-ordeal performers and observers was not, $t(49)=$ $1.45, p=.15$; this finding suggests that the high-ordeal ritual was associated with greater levels of generosity for both performers and observers than the low-ordeal ritual.

Focusing on the high-ordeal group (performers and observers), we performed a bootstrapping analysis and found that pain correlated with donations $(r=.36, p<$ .01). Notably, this effect held even after controlling for age, religiosity, and temple attendance- $95 \%$ confidence interval $(\mathrm{CI})=[.09, .66], p<.05$. To further assess the effect of perceived pain on donations, we divided the high-ordeal group into four quartiles based on participants' pain ratings. The overall difference among quartiles was significant, $F(3,46)=3.34, p<.05$. A linear polynomial contrast on these quartiles was highly significant, $F(1,46)=8.13, p<.01$, which indicates that higher levels of perceived pain were directly associated with greater donations (Fig. 1e). There were no significant differences between experienced pain (performers) and perceived pain (observers). The number of piercings did not predict how much participants donated, which suggests that effects were driven by subjective experiences of pain (Hadjistavropoulos et al., 2011). There were no differences between groups in religiosity or temple attendance, which indicates that responses did not arise from intrinsic differences in religiosity or familiarity effects but rather from the ritual conditions.

In line with modern intergroup theories, low-ordeal participants expressed the most parochial identities $(M=$ $1.71, S D=6.50$ ), seeing themselves as more Hindu than high-ordeal observers $(M=3.03, S D=6.50)$ and highordeal performers $(M=7.13, S D=3.46)$, who both favored the more inclusive Mauritian identity (Fig. 1c). An ANOVA showed a main effect of group on identity, $F(2$, $83)=5.16, p<.01$. The difference between participants in the low-ordeal ritual and high-ordeal ritual (performers and observers combined) was significant, $t(84)=2.11$, $p<.05$, as was that between high-ordeal observers and performers, $t(49)=2.54, p<.05$; these findings suggest that the intensity of the ordeal amplified the more inclusive social identity. A bootstrapping analysis revealed that greater judgments of pain predicted more inclusive identities $(r=.28,95 \% \mathrm{CI}=[.01, .53], p<.05)$. However, there was no correlation between self-identification and donations, which suggests that the two were independent effects of ritual intensity.

These findings support long-standing anthropological conjectures about the cooperative effects of intense rituals (Durkheim, 1912). We offer the first natural demonstration that suffering predicts prosociality by capitalizing on intense, real-world stimuli that would be hard to manipulate in the laboratory. Furthermore, our study links recent experimental findings that perceived pain increases prosociality (Olivola \& Shafir, 2013) with field experiments showing that extreme rituals promote empathic arousal among observers of the ordeals of actors (Konvalinka et al., 2011; Xygalatas, Konvalinka, Roepstorff, \& Bulbulia, 2011). These results suggest that costly displays of group commitment (though apparently wasteful) may be conserved because they intensify prosocial behaviors and attitudes among the wider community (Henrich, 2009; Sosis \& Bressler, 2003).

Finally, we note that identity always functions in a social context (Tajfel, 1984). In the context of a public ritual that recognizes the Hindu majority group, situated in a larger community whose members hold multiple identities, ritual intensity enhanced the superordinate national identity (also see Clingingsmith, Khwaja, \& Kremer, 2009). Overall, extreme rituals appear to amplify prosocial attitudes and behaviors, and direct or empathic experiences of pain may be the link connecting these ordeals to prosociality.

\section{Author Contributions}

D. Xygalatas developed the study concept. D. Xygalatas, P. Mitkidis, R. Fischer, P. Reddish, and J. Bulbulia designed the experiment and collected the data. J. Skewes and D. Xygalatas developed stimuli, and J. Skewes provided technical support. D. Xygalatas, A. Roepstorff, R. Fischer, and J. Bulbulia analyzed and interpreted the data and wrote the article. A. W. Geertz contributed to revising the paper. All authors provided critical revisions and approved the final version of the article for submission.

\section{Acknowledgments}

Many thanks to Chris Frith and Uta Frith for commenting on the manuscript, and the Kovil Montagne in Mauritius for practical and ethical support of this study.

\section{Declaration of Conflicting Interests}

The authors declared that they had no conflicts of interest with respect to their authorship or the publication of this article.

\section{Funding}

This research was supported by the Velux Foundation; MINDLab, the Religion, Cognition and Culture Research Unit, and the Interactive Minds Centre at Aarhus University; LEVYNA Laboratory for the Experimental Research of Religion 
(CZ.1.07/2.3.00/20.0048) at Masaryk University; the Mauritian Laboratory for Experimental Anthropology; and Victoria University Research Fund Grant No. 8-3046-108855.

\section{References}

Aronson, E., \& Mills, J. (1959). The effect of severity of initiation on liking for a group. Journal of Abnormal and Social Psychology, 59, 177-181.

Atran, S., \& Henrich, J. (2010). The evolution of religion: How cognitive by-products, adaptive learning heuristics, ritual displays, and group competition generate deep commitments to prosocial religions. Biological Theory, 5, 18-30.

Choi, J., \& Bowles, S. (2007). The coevolution of parochial altruism and war. Science, 318, 636-640.

Clingingsmith, D., Khwaja, D., \& Kremer, M. (2009). Estimating the impact of the Hajj: Religion and tolerance in Islam's global gathering. The Quarterly Journal of Economics, 124, 1133-1170.

Durkheim, É. (1912). Les formes élémentaires de la vie religieuse [The elementary forms of religious life]. Paris, France: Alcan.

Festinger, L. (1957). A theory of cognitive dissonance. Stanford, CA: Stanford University Press.

Gaertner, S. L., \& Dovidio, J. F. (2000). Reducing intergroup bias: The common ingroup identification model. Philadelphia, PA: Psychology Press.

Ginges, J., Hansen, I., \& Norenzayan, A. (2009). Religion and support for suicide attacks. Psychological Science, 20, 224230.

Hadjistavropoulos, T., Craig, K. D., Duck, S., Cano, A., Goubert, L., Jackson, P. L., \& Fitzgerald, T. D. (2011). A biopsychosocial formulation of pain communication. Psychological Bulletin, 137, 910-939.

Henrich, J. (2009). The evolution of costly displays, cooperation, and religion: Credibility enhancing displays and their implications for cultural evolution. Evolution \& Human Behavior, 30, 244-260.

Hornsey, M. J., \& Hogg, M. A. (2000). Assimilation and diversity: An integrative model of subgroup relations. Personality and Social Psychology Review, 4, 143-156.
Irons, W. (2001). Religion as a hard-to-fake sign of commitment. In R. Nesse (Ed.), Evolution and the capacity for commitment (pp. 292-309). New York, NY: Russell Sage Foundation.

Konvalinka, I., Xygalatas, D., Bulbulia, J., Schjoedt, U., Jegindø, E.-M., Wallot, S., . . . Roepstorff, A. (2011). Synchronized arousal between performers and related spectators in a fire-walking ritual. Proceedings of the National Academy of Sciences, USA, 108, 8514-8519.

Ng, T.-W. C., \& Verkuyten, M. (2010). Intergroup evaluations, group indispensability and prototypicality judgments: A study in Mauritius. Group Processes E Intergroup Relations, 13, 621-638.

Norenzayan, A., \& Shariff, A. F. (2008). The origin and evolution of religious prosociality. Science, 322, 58-62.

Olivola, C. Y., \& Shafir, E. (2013). The martyrdom effect: When pain and effort increase prosocial contributions. Journal of Behavioral Decision Making, 26, 91-105. doi:10.1002/ bdm.767

Sosis, R. (2003). Why aren't we all Hutterites? Human Nature, 14, 91-127.

Sosis, R., \& Bressler, E. (2003). Cooperation and commune longevity: A test of the costly signaling theory of religion. Cross-Cultural Research, 37, 211-239.

Tajfel, H. (1984). Intergroup relations, social myths and social justice in social psychology. In H. Tajfel (Ed.), The social dimension (Vol. 2, pp. 695-715). Cambridge, England: Cambridge University Press.

Tajfel, H., Billig, M. G., Bundy, R. P., \& Flament, C. (1971). Social categorization and intergroup behavior. European Journal of Social Psychology, 1, 149-178.

World Values Survey. (2012). WVS 2010-2012 Questionnaire. Retrieved from http://www.worldvaluessurvey.org/wvs/ articles/folder_published/article_base_136/files/WVS_ 2010-2012_REVISED_OCT_2011.pdf

Xygalatas, D., Konvalinka, I., Roepstorff, A., \& Bulbulia, J. (2011). Quantifying collective effervescence: Heart-rate dynamics at a fire-walking ritual. Communicative \& Integrative Biology, 4, 735-738. 